of the main theme and so prepared the way for the succeeding contributed papers. The range of topics covered is well illustrated by the following list of the twelve sections: solid-state chemistry, thermodynamics of electrolytes, corrosion, theory of double-layers, electro-analytical methods, applications (electroplating, anodizing), nonaqueous electrolytes, molten salts, fuel cells, electrode processes, electrochemical processes, electrowinning and electrorefining. The major sections are those concerned with fundamental research, and these give substance to Prof. J. O'M. Bockris's comments in the foreword that electrochemical research is now heavily concerned with electrode kinetics ('electrodics') and with kinetics and theories of electrode processes to the virtual exclusion of thermodynamic equilibrium studies. The sections on applied electrochemistry will prove no less interesting to those concerned with applications, but we consider that these sections might with advantage have been brought together, so permitting a greater continuity in the theoretical sections.

It is invidious perhaps to single out individual contributions. The review papers by chairmen Ross Macdonald (and C. A. Barlow) and by J. O'M. Bockris on the theory of the double-layer and electrode processes respect. ively are of particular interest because of the difficulties attending work in these fields. Perhaps not unexpectedly the number of contributions to these sections were not as numerous as in some of the other sections. In the section on electrode processes, a paper by Horiuti, Matsuda, Enyo and Kita on the mechanism of the hydrogen evolution reaction is of considerable interest, as also is that by Christov on the application of quantum mechanics to electrode kinetics. In the section on electrochemical processes mention should be made of the chairman's address and a stimulating paper by Bockris, Devanathan and Müller on the structure of charged interfaces. But this is to mention a few among the many excellent papers the degree of importance of which will vary according to the particular interests of the reader.

The production of the book is excellent, and Pergamon Press have fully maintained the high standard set by $\mathrm{F}$. Gutmann and M. Bloom, who organized the Conference and, with J. A. Friend, edited the Proceedings. The price at $£ 10$ is not excessive for such a book.

R. F. Philitips

N. A. Hampson

\section{NUCLEAR AND RADIOCHEMISTRY}

\section{Nuclear and Radiochemistry}

By Dr. Gerhart Friedlander, Joseph W. Kennedy and Dr. Julian Malcolm Miller. Second edition. Pp.xi+585. (New York and London: John Wiley and Sons, Inc., 1964.) $68 \mathrm{~s}$

$\mathrm{F}$ RIEDLANDER, Kennedy and Miller" is still recognizably the same excellent text as "Friedlander and Kennedy", though the format is new, the order of the chapters has been changed, and there are substantial additions to the subject-matter, as well as some deletions. On balance, the new edition is longer by roughly one-third compared with its predecessor. Prof. J. M. Miller of Columbia University has replaced the late Prof. J. W. Kennedy as author, though Kennedy's name has deservedly been retained on the title-page. Not unnaturally, the book still has an American slant, but this in no way invalidates it for other countries.

In their preface the authors state that "the book is still intended as a text for an advanced undergraduate or firstyear graduate course; but a significant aspect of its modernization is found in the greater depth of treatrnent accorded to many topics, particularly theorotical ones". The new material includes greatly expanded treatments of nuclear reactions and radioactive decay processes, accounts of new types of accelerators, counters and other instru- ments, and two completely new chapters, the first on models of the nucleus, and the second on the Mössbauer effect and other nuclear processes that can be made to yield chemical information.

It is characteristic of the book that, whatever topic one turns to, one finds the essential points well and clearly stated. It has been my experience more than once, after wrestling with a tricky point, to find the conclusion that $I$ have extracted with difficulty from other sources set down in simple terms in Nuclear and Radiochemistry.

The title and contents of the book prompt the questions: What is nuclear chemistry? and What is radiochemistry? The claim that the book is "written by chemists for chemistry students" is a valid one, yet of the fifteen chapters, only three deal with specifically chemical topics, and only two others contain sections of any length on ehemical subjects. Moreover, the chapter on radioactive tracers has actually been shortened in the new edition.

I first remember the term 'nuclear chomistry' in the annual reports of the Chemical Society for 1935, when it was used to refer to the science of nuclear transmutations, on the analogy between chemical roactions, in which atoms are conserved, and nuclear reactions, in which nucleons are conserved. It is now often used to mean something like "nuclear studies carried out by chemists". Some of the properties investigated in this context undoubtedly belong to the realm of physics rather than chemistry, but chemists do a large share of the work because success depends on preparing pure specimens and on carrying out efficient chemical separations at the end of the experiment.

However, the term is also used in a much wider sense. Coryell, in his foreword to the English edition of Haissinsky's Nuclear Chemistry and its Applications, speaks of it including "nuclear reactions, radioelements, radiochemistry, isotopo chemistry, radiation chemistry, and tracer applications", and all those fields and more are indeed covered in Haissinsky's book, even though Haissinsky's own definition of nuclear chemistry is merely "the study of the transmutations and transformations of nuclei".

'Radiochemistry' is likewise used in both broad and restricted senses. Originally it referred to the chemical effects of ionizing radiations, but this is now a matter of history only. Later it was applied to the chemistry associated with the natural radioelements, though excluding the ordinary chemistry of thorium and uranium, in which radioactivity played no part. When artificial radioactivity was discovered, the term was of course extended to the new radioactive species. A further extension was to the radiotracer field, in which both natural and artificial radioelements find numerous applications. Many authors still stop at this point, and leave the lively subjects of hot atom chemistry and nuclear chemistry (in the limited sense) largely outside the scope of 'radiochemistry'. Others again treat the subject as if it were primarily a collection of manipulatory and measuring techniques. Radiochimica Acta, on the other hand, adopts a more eclectic view-one which I also favour. There seems indeed no good reason why 'radiochemistry' should not include all aspects of the interaction of chemistry with radioactivity, with the sole exception of most of the radiation chemistry aspects, which involve by and large a distinct set of concepts and techniques.

This discussion is relevant to the book under review, because it needs to be appreciated that Nuclear and Radiochemistry is primarily a text-book of nuclear chemistry in the restricted sense, and only secondarily a general text-book of radiochemistry. The nucleus itself, nuclear reactions and radioactivity are discussed very fully, since they form the principal subject of investigation in nuclear chemistry, and so are the techniques needed. Other radiochemical topics are treated much more briefly, and very largely from the point of view of the nuclear chemist. In saying this, no criticism is intended, but rather a definition of the scope of this important work. H. A. C. McKAX 